\title{
A EDUCAÇÃO AMBIENTAL EM ÁREAS COSTEIRAS: O USO DA WEB COMO FERRAMENTA NA FORMAÇÃO DO OCEANÓGRAFO
}

\author{
GUERRA, A.F.S. \\ Centro de Ensino Superior de Ciências Tecnológicas, da Terra e do Mar, Centro de \\ Ensino Superior de Ciências Humanas e da Comunicação - Mestrado em Educação - \\ Universidade do Vale do Itajaí- UNIVALI Rua Uruguai, 458 - Cx Postal 360, CEP: 88302- \\ 202 - Itajaí - SC. guerra@cttmar.univali.br
}

RESUMO

\begin{abstract}
Os Parâmetros Curriculares Nacionais (PCN) elevaram a Educação Ambiental (EA), no ensino Fundamental e Médio, à condição de tema transversal. No entanto, por lacunas em sua formação profissional ou por falta de oportunidades de atualização, tanto profissionais como futuros professores, muitas vezes não conseguem utilizar os conhecimentos específicos sobre os ambientes costeiros como conteúdos de ensino e/ou práticas para a Educação Ambiental, seja ela formal ou informal. Isto se dá por falta de um maior aprofundamento filosófico e epistemológico sobre os fundamentos e práticas em EA. Assim, convém questionar de que formas o futuro oceanógrafo pode incorporar à sua formação técnico-científica a educação ambiental que vem sendo integrada à Educação como um todo através da transversalidade do currículo, nos três graus de ensino. Este trabalho procura discutir as possibilidades de integração entre a EA em áreas costeiras e as Tecnologias de Informação e Comunicação (TIC), na formação do oceanógrafo, uma vez que a interação entre tecnologias como a Internet e a educação só têm sentido se utilizadas, ao mesmo tempo, como ferramentas pedagógicas para disseminação do saber e como objetos de estudo.
\end{abstract}

Palavras chave: Educação Ambiental, Páginas Web

\section{ENVIRONMENTAL EDUCATION IN COASTAL AREAS: THE USE OF THE WEB AS A TOOL IN THE TRAINING OF THE OCEANOGRAPHER}

\begin{abstract}
The Parâmetros Curriculares Nacionais - PCN (National Curricular Parameters) raised Environmental Education (EE) in Elementary and Secondary school to the condition of a transversal theme. However, due to omissions in their professional training or a lack of opportunities to keep up todate, both professionals and future teachers are often unable to use their knowledge of coastal ecosystems as teaching content and/or practice of Environmental Education, whether formal or informal. This situation arises from the lack of deeper philosophical and epistemological study on the fundamentals and practices of EE. It is, therefore, appropriate to question in what forms the future oceanographer could incorporate technical-scientific training into the environmental education. EE is being integrated to Education as a whole through the curricular transversality in all levels of education. This work seeks to discuss the interaction between Information and Communication Technologies (ICT) and EE in coastal areas, since the interaction between technologies like the Internet and education can only be considered worthwhile if they are used, at the same time, as teaching tools for the dissemination of knowledge and objects of study.
\end{abstract}

Key Words: Environmental Education, websites. 


\section{INTRODUÇÃO}

Podemos considerar que a Educação Ambiental (EA) no Brasil apresentou um avanço significativo após a RIO 92 (Conferência sobre Meio Ambiente e Desenvolvimento). Nela foram produzidos a "Agenda 21" e o "Tratado de Educação Ambiental para Sociedades Sustentáveis e Responsabilidade Global", que reconhecem o papel central da educação na formação de valores e na ação social e para criar sociedades sustentáveis e eqüitativas (socialmente justas e ecologicamente equilibradas). Neste contexto a EA pode ser definida como sendo um processo permanente baseado no respeito a todas as formas de vida, o que requer responsabilidade individual e coletiva em níveis local, nacional e planetário.

Seguindo a tendência sócio-ambiental (Medina, 1994), na educação brasileira já é significativa a produção de materiais para a EA formal e não formal (Trajber \& Manzochi, 1996; Trajber \& Da Costa, 2001), antes mesmo dos Parâmetros Curriculares Nacionais (PCN) elevarem o meio ambiente $e$ a $E A$ à condição de tema transversal, no ensino Fundamental. Assim, o sentido que os PCN procuram dar à transversalidade e a interdisciplinaridade é propor a discussão daquele e outros temas (pluralidade cultural, ética, saúde, orientação sexual) em todas as áreas de estudo, ou seja, não somente individualizada numa única disciplina ou especialização, mas de uma forma interdisciplinar. No que diz respeito ao ensino formal, a grande novidade da Política Nacional de Educação Ambiental é que ela propõe a integração da EA às disciplinas do currículo, atendendo às recomendações da UNESCO e das principais conferências internacionais nas quais o conceito de EA foi sendo construído (Tibilisi, 1987; Rio 92; Tessalonica, 1997, entre outros).

Segundo a lei oㅜ 9795, de 27/04/1999 em seu artigo segundo, a EA "é um componente essencial e permanente da educação nacional" no ensino formal e não-formal, devendo abranger, de forma integrada todos os ní- veis e modalidades do processo educativo, ou seja, os currículos e propostas curriculares das instituições de ensino públicas e privadas, englobando assim: Educação Infantil; Ensino Fundamental; Ensino Médio, Educação Superior; Educação Especial; Educação Profissional; Educação de Jovens e Adultos. Desta forma, a lei torna obrigatório tratar a dimensão ambiental em todos os níveis e modalidades de ensino. Mas, convém chamar a atenção para a recomendação de que ela não deverá ser implantada como disciplina específica no currículo. Aliás, é vetado por esta lei tratar a EA como uma disciplina. Esta é também a recomendação dos PCN do Ensino Fundamental.

Essa situação nos leva, obrigatoriamente, a refletir sobre os desafios da formação continuada e permanente de professores para 0 processo de incorporação da Dimensão Ambiental nos currículos do Ensino Fundamental e Médio e, no Ensino Superior, dos próprios Cursos de Graduação como o de Oceanografia, uma vez que constata-se em nossa região que alunos do curso acabam se direcionando para a função docente em escolas públicas em disciplinas como a Biologia e Química, por exemplo. Além disso, no próprio ensino superior a função docente exige determinadas competências pedagógicas do pesquisador para atuar no ensino.

Guerra \& Taglieber (2000) questionam como realmente instrumentalizar os docentes e futuros docentes para o desenvolvimento de conhecimentos, habilidades e competências necessárias para a efetiva implementação da EA como uma das dimensões do processo educacional. Segundo eles, também seria necessário refletir sobre o papel da Universidade e da escola pública como instituições onde deverão produzir-se essa inserção da Dimensão Ambiental no currículo, o que envolve as atividades de diferentes agentes sociais (professores, alunos, lideranças comunitárias), como das universidades e organizações governamentais e não governamentais que elaboram e fiscalizam a aplicação das políticas públicas 
relacionadas a educação e as questões ambientais.

No caso específico da formação do oceanógrafo, por exemplo - embora com uma sólida formação básica de natureza interdisciplinar voltada ao gerenciamento, avaliação, conservação e manejo dos recursos naturais dos ambientes marinhos e costeiros, entre outras -, por lacunas em sua formação profissional ou por falta de oportunidades de atualização, os profissionais que hoje os três cursos reconhecidos no país estão colocando no mercado de trabalho, muitas vezes não desenvolveram em seus cursos habilidades e competências, e também atitudes e valores éticos suficientes para promover uma "transposição didática" dos conhecimentos científicos específicos para desenvolver práticas e projetos de EA em áreas costeiras, seja ela formal ou informal.

Para Guerra (2000), devido a essas lacunas os futuros profissionais que poderiam atuar como educadores ambientais, muitas vezes não sabem utilizar, por exemplo, conceitos específicos sobre a complexidade e diversidade dos ecossistemas costeiros (mata Atlântica, praias, dunas, manguezais, restingas), utilizando-os como conteúdos de ensino e/ou ferramentas para a EA. Segundo o autor, aqueles que vivem e trabalham nessas regiões, e também os futuros(as) educadores(as), precisam ter um conhecimento destes ambientes para poder explorá-los de forma didática com alunos professores ou comunidades, utilizando-se para isso de conhecimentos biológicos específicos, mas também levando em conta as dimensões econômica, social, cultural e ética que envolvem os conflitos de interesses que provocam uma série de problemas ambientais nestas áreas, dentre eles a ocupação urbana, uma vez que, conforme a AGENDA 21 na zona costeira vive aproximadamente $60 \%$ da população mundial em uma faixa de $60 \mathrm{~km}$ de raio dos oceanos.

$\mathrm{Na}$ área de Oceanografia, Santos (1999) questiona se as propostas curriculares dos cursos até hoje existentes estão realmente voltadas às necessidades que a sociedade e o mercado de trabalho impõem; se as habilidades exigidas abrangem os diversos campos de trabalho e os que ainda não foram explorados na Oceanografia.

É a partir desses questionamentos que queremos incluir a EA como um dos campos de trabalho do oceanógrafo. Em nosso entendimento, a Dimensão Ambiental de que falamos poderia ser entendida no sentido da transversalidade também na nova matriz curricular que vem sendo discutida para os cursos de Oceanografia. Dentro desta perspectiva, inserir a EA de uma forma transversal e interdisciplinar no currículo, é bem mais que aprofundar somente conteúdos de Ecologia e desenvolver competências técnicas para o gerenciamento costeiro. Envolve também mudanças conceituais, individuais e coletivas, mudanças de atitudes, compromisso social em assumir ações efetivas de intervenção na resolução de problemas ambientais em parceria com atores e atrizes das comunidades litorâneas, com órgãos governamentais e ONGs, como também mudança de valores, ou seja, modificações da própria subjetividade, o que só se atinge a partir da sensibilização e da percepção de cada um, para que se passe da "consciência ingênua" para a "conscientização" (Freire, 1988) em relação aos graves problemas ambientais, especialmente dos ambientes costeiros, e que a sociedade contemporânea enfrenta, em nível local e global.

Neste sentido mais amplo, a EA pode ser entendida na visão de Medina (1998), como sendo um:

“... processo que consiste em propiciar às pessoas uma compreensão crítica e global do Ambiente... (...) a construção de relações sociais, econômicas e culturais capazes de respeitar e incorporar as diferenças, (minorias étnicas, populações tradicionais), a perspectiva da mulher, e a liberdade para decidir caminhos alternativos de desenvolvimento sustentável respeitando os limites dos ecossistemas, substrato de nossa própria possibilidade de so- 
brevivência como espécie."

A afirmação anterior complementa o que encontramos no artigo primeiro da Lei da EA, entendida como "os processo pelos quais o indivíduo e a coletividade constroem valores sociais, conhecimentos, habilidades, atitudes e competências voltadas para a conservação do meio ambiente, bem de uso comum do povo, essencial à sadia qualidade de vida $e$ sua sustentabilidade".

Embora possa se fazer uma ressalva a afirmação um tanto antropocêntrica e utilitarista do ambiente no texto da Lei, a mesma e os outros instrumentos e conferências citados até aqui nos levam a um novo problema para reflexão: Qual é o "nicho" da EA nas pesquisas em andamento nos Cursos de Oceanografia no Brasil? Em um rápido levantamento nos sites de quatro cursos do país (UERJ, FURG, UNIVALI e UFES), encontramos a situação a seguir.

Na FURG, na descrição da proposta de sua nova estrutura curricular, encontramos uma justificativa para inclusão do tema "educação ambiental" entre outros tantos que vem sendo abordados nos trabalhos dos acadêmicos do curso, mas fazendo parte da "formação optativa" dos mesmos. Em termos de atividades de pesquisa específica em EA, estas se realizam no Centro de Educação e Formação Ambiental Marinha do Museu Oceanográfico da FURG.

NA UERJ, a EA é citada como fazendo parte da área de Oceanografia Biológica. Já na UFES, apesar do Curso de Oceanografia estar ligado ao Departamento de Ecologia e Recursos Naturais, na apresentação da página Web que trata do "campo de atuação do oceanógrafo" formado pelo curso, não encontramos nenhuma menção direta a linhas de pesquisa em EA, e nem mesmo como disciplina optativa.

Já na UNIVALI, encontramos duas linhas de pesquisa relacionadas à EA. A primeira, ligada ao Laboratório de Educação Ambiental (LEA), com ênfase na EA em áreas litorâneas, modelagem ecológica, reciclagem de resíduos sólidos e a pesquisa de Monitoramento
Ambiental Voluntário (MAV). A segunda linha é a de Planejamento da Paisagem Costeira. Com relação a disciplinas, uma fundamentação teórica básica em EA e práticas pedagógicas de percepção e sensibilização, na forma de atividades educativas e oficinas, foram incluídas no programa da disciplina de Ecologia e Cidadania II, oferecida no $10^{\circ}$ período do curso.

Em nossa visão de educador, numa avaliação inicial, percebemos que a Dimensão Ambiental e a EA na perspectiva aqui apresentada, ainda não ocupam o devido espaço nas universidades citadas, bem como nas discussões das propostas de reformulação das Diretrizes Curriculares dos Cursos de Oceanografia no país, e que "deverão orientar os procedimentos para autorização de habilitação de novos cursos, ou reconhecimento e renovação dos cursos já existentes." (Santos, 1999). Nesta perspectiva, seria importante discutir de que formas o futuro oceanógrafo poderia incorporar à sua formação técnico-científica a Dimensão Ambiental, no sentido pedagógico e epistemológico da mesma (Guerra \& Taglieber, 2000) que vem sendo proposta à educação como um todo, através da inserção da transversalidade no currículo dos três graus de ensino.

Agora, é importante deixar claro, mais uma vez, que não estamos afirmando que os cursos citados não têm uma preocupação com a formação ambiental, ao contrário, nessa visão mais ampliada que trazemos à discussão, todo oceanógrafo seria também um educador ambiental, habilitado a organizar programas e projetos interdisciplinares de EA numa visão sistêmica e não só naturalista, uma vez que aos seus conhecimentos ecológicos e sobre gerenciamento ambiental de áreas costeiras, entre outros, estariam incluídas o desenvolvimento de competências e habilidades, bem como de valores éticos e de cidadania individual e planetária.

Dessa forma esse profissional passaria a atuar, por exemplo, junto a comunidades locais de pescadores artesanais e maricultores, 
e, nas escolas, junto a crianças, jovens e na formação continuada de professores das escolas de áreas litorâneas. È importante lembrar que, historicamente, desde o "descobrimento" a população brasileira ocupou e ocupa o litoral brasileiro dentro de um modelo predatório de desenvolvimento (in)sustentável que pode ser resumido como de produção->consumo->produção (de lixo e outros poluentes e contaminantes). Hoje, estas populações interagem e transformam e alteram a paisagem das áreas costeiras, a partir de problemas como as migrações internas (Polete,1999) e a ocupação urbana desordenada das mesmas (Toledo, 1997), provocando sérios danos aos ecossistemas e a paisagem costeira, com reflexos na economia, no turismo e lazer destas mesmas populações.

Diante do exposto até aqui, este trabaIho procura descrever uma experiência realizada numa disciplina do Curso de Oceanografia da UNIVALI onde se procura inserir aspectos do que é a Dimensão Ambiental como processo educativo, apresentando e discutindo uma fundamentação teórica básica em EA em áreas costeiras, integrando-a com as Tecnologias de Informação e Comunicação (TIC). Foi a forma que encontramos de integrar a EA e utilizar essas tecnologias na formação do oceanógrafo no desenvolvimento de valores éticos e estéticos. Essa intervenção pedagógica se justifica uma vez que a interação entre tecnologias como a Internet e a educação só têm sentido se utilizadas, ao mesmo tempo, como ferramentas pedagógicas para disseminação do saber e como objetos de estudo (Belloni, 1999).

\section{METODOLOGIA}

Buscando discutir fundamentos teóricometodológicos básicos e desenvolver práticas de EA, e também para instrumentalizar os alunos no uso das TIC para produção de páginas Web para EA em áreas costeiras, organizamos um projeto-piloto (Guerra, 1997, 1999, 2000a) com alunos dos semestres 1998/2 a
2000/2), da disciplina de "Ecologia e Cidadania Il", do Curso de Oceanografia do Centro de Ciências Tecnológicas, da Terra e do Mar CTTMar da Universidade do Vale do Itajaí-SC.

Nesse Projeto, criou-se uma página Web (homepage) no endereço eletrônico http:// www.cttmar.univali.br/ guerra, em que estão sendo produzidas e disponibilizadas para acesso, informações, atividades de ensino, pequenos projetos e materiais educativos, na forma de hipertextos. Estas páginas Web são produzidas pelos próprios alunos ao longo da disciplina, e dizem respeito a problemas ambientais. Com isto espera-se enriquecer o processo de interação e a cooperação entre os diferentes atores e atrizes do processo de aprendizagem (alunos e professores em formação, pesquisadores e técnicos) e todos aqueles que acessarem este site.

A cada início de semestre da disciplina é realizado um questionário, para identificar as representações dos alunos sobre os conceitos de meio ambiente e EA. Os dados coletados são analisados e discutidos com os próprios alunos, em sala de aula, utilizando as seguintes categorias: antropocêntrica, naturalista e globalizante, propostas por Reigota (1995).

As discussões em sala de aula são intercaladas com atividades e oficinas de percepção ambiental. À medida que as representações dos alunos vão se ampliando ao longo das discussões, elaboram-se instrumentos para avaliação destas percepções, como os mapas conceituais (Ver anexos). Os arquivos com textos e apresentações das aulas elaboradas pelo professor em Powerpoint $₫$ ou Microsoft Word®in, são disponibilizados na rede do CTTMar/UNIVALI para livre acesso através dos computadores, ou no próprio site da disciplina.

Após algumas semanas de trabalho e a partir da reflexão teórica das representações dos alunos sobre meio ambiente e a EA, suas tendências, objetivos e práticas, se procura organizar com os alunos os temas e trabalhos 
a serem desenvolvidos na forma de páginas Web e como trabalho final da disciplina.

As páginas Web produzidas são disponibilizadas no site da disciplina que se constitui assim em um Ambiente de Aprendizagem Cooperativa (McConnel, 1994). O site começou a ser produzido cooperativamente por um grupo de sete alunos no segundo semestre de 1998, sob orientação do profesor-pesquisador e o auxílio de um técnico do Laboratório de Informática do CTTMar/UNIVALI. O ambiente utiliza como mídia a Internet, e para edição das páginas os alunos utilizam as ferramentas encontradas na rede como, por exemplo, o Netscape Composer $\AA$, o Microsoft FrontPage $\AA^{\circledR}$, e o Macromedia Dreamweaver $\AA^{\circledR}$.

Assim, a página Web de abertura da disciplina foi desenvolvida ao final do primeiro semestre de 98, com links para as demais páginas que foram sendo criadas: "Breve Histórico"; "Quem somos"; "Nossos Objetivos"; "Atividades Educativas"; "Poesias Ecológicas" e "Trabalhos dos Alunos".

Um grupo de quatorze alunos do semestre 99/1, elegeu a Educação em Ambientes Costeiros como "tema gerador" de seus trabaIhos, envolvendo os seguintes temas: "Manguezais", "Conhecendo as Dunas"; "A problemática do lixo"; "Modificações na paisagem em nossas praias"; "Conhecendo a Maricultura" e "Programa de Proteção da Praia Brava-SC".

Os dezesseis alunos do semestre 99/2 retomaram os temas "Manguezais", "Maricultura" e "Praia Brava", enquanto um outro desenvolveu o tema sobre a "Água". No semestre 2000/1 nove alunos criaram três novas páginas: "Oceanos", "Oficina do Mar", "Os conflitos da pesca no litoral catarinense". A estas, foi acrescida pelo professor a página "Cidadania e Meio Ambiente".

A cada final de semestre, concluída a organização dos trabalhos e atividades de ensino, as páginas Web são editadas pelos alunos para serem disponibilizadas no site da disciplina. No entanto, antes de serem disponibilizados na Internet estes trabalhos são revisados quanto ao aspecto científico dos mesmos, através de uma parceria que se concretizou ao longo dos últimos dois anos de trabalho com pesquisadores dos cursos de Oceanografia e Ciências Biológicas da UNIVALI, que vem participando na orientação dos alunos na revisão dos trabalhos a serem inseridos nas páginas $W e b$.

No semestre 2000/2 dezoito alunos produziram nove páginas: "Qualidade de água da praia central de Balneário Camboriú - SC"; "Tartarugas marinhas"; "Rejeitos fármacos: Um novo poluente das águas", "Marismas", "Metodologia de Revestimento Riley - restauração de manguezais"; "Monitoramento Ambiental Voluntário como atividade educativa nas escolas"; Aspectos Ambientais da Planície Costeira da região Centro-norte catarinense" e "Os oceanos estão morrendo", as quais estão disponibilizadas no site.

Usando como subsídio parte da pesquisa de doutorado com o Projeto EducAdo Educação Ambiental em áreas costeiras usando a Web como suporte (Guerra, 1999, 2000 , 2001), a partir do semestre 2000/1, a avaliação da experiência descrita até aqui, foi organizada na forma de questionário, com questões abertas e fechadas, para determinar o conhecimento e habilidades dos alunos no uso do computador e da Internet, antes e ao final da disciplina, bem como os pontos positivos e negativos em relação aos seguintes aspectos: uso do espaço físico e do equipamento no laboratório de informática; o assessoramento do professor; interação professor $<\rightarrow$ aluno $<\rightarrow$ aluno; comunicação entre professor e colegas através da lista de discussão da disciplina, e as formas de organização e superação das dificuldades para organização das páginas Web pelos grupos. Ainda, questões sobre como fariam uso deste conhecimento de EA e uso da informática em sua vida acadêmica e na futura atividade profissional.

No semestre seguinte o questionário foi reformulado, acrescentando-se uma questão para analisar o nível de aprendizagem dos recursos informatizados pelos alunos (Internet, construção da própria página Web, uso da lis- 
ta de discussão, e-mail), de acordo com as seguintes categorias: aprendizagem individual; compreensão das vantagens da Internet como ferramenta educacional e de pesquisa; inclusão, ou seja, incorporação do uso das ferramentas de acesso à rede em suas atividades cotidianas; adoção do uso da rede para solucionar questões imediatas de pesquisa ou de caráter variado; transformação do nível de conhecimento mais apurado, passando a utilizar a rede como fonte de informação e comunicação; cooperação para produzir conhecimentos de forma individualizada e coletivamente com a turma/grupo/professor; construção do conhecimento a partir da prática efetiva do uso dos recursos e desenvolvimento de habilidades técnicas no uso dos recursos.

\section{RESULTADOS E DISCUSSÃO}

Até o momento, sessenta e quatro alunos cursaram a disciplina, produzindo um total de vinte páginas Web, com temas extremamente variados que permitem uma compreensão bem ampla sob aspectos específicos e problemas dos ambientes costeiros.

A partir de alguns relatos verbais e trabalhos dos alunos na disciplina, verificamos o surgimento de alguns obstáculos relacionados à compreensão dos conceitos de meio ambiente e EA, e a confusão entre estes e conceitos específicos de Ecologia. Após as atividades e discussões teóricas, os alunos acabam concluindo que suas representações individuais e sociais iniciais, acabam sendo, na maioria das vezes, essencialmente "naturalistas" ou então "antropocêntricas", conforme as categorias propostas por Reigota (1995). Discutimos então a hipótese destas representações serem fruto da própria formação profissional na área biológica, essencialmente voltada para conceitos ecológicos, sem levar em conta outros aspectos da problemática ambiental: sociais, econômicos, políticos, éticos e legais. Esta visão reducionista e antropocêntrica impede a compreensão do meio ambiente dentro de uma visão globalizante (Reigota, op. cit.) ou sócio- ambiental (Medina, 1994), que preferimos chamar de holística ou sistêmica.

Espera-se que, ao final da disciplina, a fundamentação teórica, as oficinas e atividades de percepção e sensibilização ambiental realizadas provoquem nos alunos uma evolução conceitual efetiva das representações iniciais, de tal forma que os futuros oceanógrafos compreendam que a EA pretende aproximar a realidade ambiental das pessoas, para que elas percebam que a Dimensão Ambiental impregna suas vidas, e que cada um tem um papel e responsabilidade social e ética sobre o que ocorre no ambiente em que vive, seja ele da natureza ou da cultura (Freire, 1983). Nesta perspectiva, a EA é uma proposta de educação para refletir sobre as formas de interações entre os seres humanos, as sociedades, os diferentes grupos sociais e a natureza, o que envolve discussões e conflitos sobre a ética e a cidadania, o direito à vida em todos os aspectos (Reigota, 1994).

Quanto ao entendimento dos limites e possibilidades da construção e uso de páginas Web como recurso para EA, convém destacar que a maioria dos alunos só tem acesso ao computador e a Internet na própria Universidade, o que causa nas primeiras aulas no Laboratório de Informática, reações tanto de receio quanto de deslumbramento frente ao computador e, principalmente, ao uso das ferramentas da Internet como o correio eletrônico e a lista de discussão.

Soma-se também ao aspecto anterior as dificuldades técnicas de acesso ao servidor da Universidade e, conseqüentemente à Internet em determinadas ocasiões, o que obriga a manter as páginas em construção armazenadas em um arquivo no servidor do Laboratório de Informática, para que os alunos possam trabalhar nas mesmas quando não conseguem acessar a rede. A mesma também serve de backup para aqueles que "perdem" seus arquivo ou páginas ou esquecem os disquetes em casa.

Quando o acesso funciona normalmente, um problema que costuma surgir também, 
é a falta de habilidade e também de paciência dos alunos para explorar a Internet e seus recursos como as bibliotecas virtuais e os próprios sites selecionados na página da Web da disciplina. Isto demonstra a falta de esclarecimento das possibilidades da Internet como ferramenta de busca e apoio à pesquisa, e não só de entretenimento e lazer.

Além disso, uma das dificuldades é também a de criar o hábito da comunicação periódica aluno-aluno-professor, via e-mail, através da lista de discussão da disciplina, para que haja troca de informações entre as pessoas do grupo. A mesma acaba sendo apenas uma lista de informação do professor aos alunos.

Quanto ao aspecto da produção das páginas Web, destaca-se o entusiasmo com os resultados alcançados quando a página Web está concluída, ao final da disciplina, considerados muito bons, segundo os relatos dos alunos, embora muitas vezes tenhamos sido forçados a usar de um certo "autoritarismo pedagógico" para que concluíssem a correção e conclusão das páginas antes do lançamento das médias finais.

Por outro lado, devemos levar em consideração que a disciplina de Ecologia e Cidadania II disponibiliza uma carga horária insuficiente para que os alunos se apropriem do uso do ambiente de aprendizagem produzido como ferramenta para aprendizagem individualizada, ou seja, de forma autônoma. Nesse aspecto concordamos com Jonassen (1996) de que a experiência em "primeira pessoa", sozinha, não é suficiente para que ocorra aprendizagem, quando se utiliza as TIC como suporte do processo de ensino-aprendizagem. Daí a sugestão que esse tipo de experiência de uso das TIC como suporte a aprendizagem seja disseminada ao longo da formação e incorporada por outras disciplinas do curso de Oceanografia.

Á crítica anterior acrescentaríamos a necessidade de criação, dentro dos cursos de Oceanografia, de uma cultura de uso da Internet como ferramenta de pesquisa (Zucchi, 1997), como também dos Ambientes de Aprendizagem virtuais, como os que estão sendo avalia- dos e desenvolvidos pelo GAVEA - Grupo de Estudos de Ambientes Virtuais de EnsinoAprendizagem da UNIVALI (http:// cehcom.univali.br/gavea/), uma parceria entre o Mestrado em Educação do Centro de Educação Superior de Ciências Humanas e Comunicação - CEHCOM e o Centro de Educação Superior em Ciências da Terra e do Mar CTTMar.

Com isso se quer propor a utilização dessas ferramentas como recursos adicionais nas práticas pedagógicas das disciplinas de formação básica e específica dos cursos, para que os alunos se apropriem das mesmas durante o processo de formação acadêmica, uma vez que a utilização das TIC é hoje uma das competências básicas exigidas na sociedade da informação e do conhecimento, em qualquer atividade profissional.

Voltando a análise da pesquisa realizada, as possibilidades para a aprendizagem cooperativa usando páginas Web como recurso, também são significativas, quando analisamos, por exemplo, alguns dos relatos que falam da condição inicial da maioria dos participantes, que nunca haviam construído antes um artefato como este.

Os depoimentos mostram que a disciplina se tornou "bem mais dinâmica" (F.S, turma 2000/2) com o "aprender fazendo" as páginas Web (L.N.S., turma 2000/1); que perceberam "como o mundo informatizado está substituindo os quadros das salas de aula, passando muito mais informação, tanto para o aluno como para o professor" (G.P, turma 2000/2). Além disso, resgatou em alguns deles o prazer de aprender de forma autônoma mas também cooperativa, "buscando solucionar problemas através de amigos do curso e da disciplina que ajudaram de forma expressiva" R.N, turma 2000/2), ou seja, despertou também o espírito de cooperação e solidariedade de ensinar ao outro o que se aprendeu, e de resolver problemas que poderiam parecer complexos para um iniciante, como, por exemplo, formatar um hipertexto, inserir uma foto na página, fazer links, entre outros. 
A criatividade dos hipertextos e materiais das páginas produzidas, e a infinidade de caminhos possíveis para a navegação através das páginas Web construídas pelos próprios alunos, foram bastante significativas. Também, foram significativas a comunicação e cooperação dos aprendentes nas trocas de informações para a resolução de problemas que surgiram durante os trabalhos de organização das páginas. A própria seleção dos temas das páginas Web e seu conteúdo parecem demonstrar uma mudança conceitual das representações naturalistas de meio ambiente, e o desenvolvimento da consciência crítica (no sentido dado por Paulo Freire) em relação aos problemas ambientais abordados por eles em seus trabalhos.

Convém destacar também como vantagem à possibilidade de professor e alunos trabalharem em parceria na construção do conhecimento - "houve aprendizagem na troca de informação aluno-professor-rede, através da página" (F.S., turma 2000/2); a solidariedade no ensinar aos outros o que se sabe e, ao mesmo tempo, aprender constantemente.

Enfim, esse processo educativo tem permitido a possibilidade de vivência de novas experiências de aprendizagem, o exercício da autonomia, tanto individual como dos grupos, na escolha, por exemplo, das melhores estratégias de planejamento das atividades a serem executadas, desde a pesquisa em diferentes fontes, escolha e formatação do material bibliográfico a ser utilizado para a organização do hipertexto; o planejamento coletivo da página Web, as revisões constantes e a resolução de problemas técnicos (um link que teima em não abrir, a inserção de uma foto ou tabela, etc.) que vão surgindo à medida que se desenvolve o processo de criação de cada uma das páginas.

A proposta de ambiente de aprendizagem proporcionou também a produção de páginas para divulgação de atividades e projetos em andamento no Curso de Oceanografia da UNIVALI, como o "Programa de Proteção da Praia Brava-SC", em parceria com a ONG "Vo- luntários para a verdade Ambiental - V Ambiental", a de "Monitoramento Ambiental Voluntário - MAV e da Oficina do Mar, entre outros.

No semestre 2000/2, três alunos se propuseram a utilizar o que aprenderam na produção de suas próprias páginas Web, para divulgação e troca de informações sobre seus Projetos de Graduação. Ainda, dois deles se mostraram dispostos a participar dos projetos em desenvolvimento sobre uso de ambientes de aprendizagem para EA, usando a Web.

A experiência descrita aqui também parece estar incentivando outros alunos do Curso de Oceanografia a freqüentarem a disciplina, uma vez que vem crescendo a participação de alunos de outros períodos, e não só dos formandos, embora alguns elogiem e outros reclamem desta heterogeneidade.

\section{CONCLUSÕES}

Retomando a questão inicial sobre a formação do oceanógrafo, os resultados preliminares do estudo na disciplina de Ecologia e Cidadania II, indicam, em primeiro lugar, que convém elaborar propostas para investigar 0 papel das TIC e do uso de ambientes de aprendizagem informatizados na formação do oceanógrafo, uma vez que esta competência não está prevista como disciplina ou atividade curricular.

Com relação à EA em áreas costeiras, com este artigo esperamos ter despertado nos colegas oceanógrafos uma reflexão sobre a possibilidade de incluir a Dimensão Ambiental no currículo e implementar pesquisas e programas de EA como parte do processo de reformulação das Diretrizes Curriculares dos Cursos de Oceanografia.

Para isso, oceanógrafos e educadores precisam integrar-se para refletir e somar esforços na re-estruturação de programas de ensino e na execução de projetos interdisciplinares que possam incorporar essa dimensão. Isso significa dizer que a transversalidade e a interdisciplinaridade não 
podem ficar apenas nos discursos ou no papel, mas que necessitam de uma ação efetiva na busca da mudança de concepções do próprio currículo, e do diálogo interdisciplinar entre as diferentes áreas do conhecimento (Oceanografia, Ciências Sociais e Ciências Humanas) por parte do corpo docente e discente do curso.

Para que isso se efetive, na práxis, esse estudo aponta também que a formação profissional do oceanógrafo, dentro da dimensão ambiental aqui proposta, necessita de um aprofundamento filosófico e epistemológico sobre os fundamentos e práticas em EA.

O que queremos dizer é que a construção da dimensão ambiental na Educação passa pela reflexão, por exemplo, da superação tanto da visão mecanicista e utilitarista, quanto da visão ecológica de natureza, construindo uma visão sistêmica ou holística dessa dimensão, fundamentada na filosofia e epistemologia (Guerra \& Taglieber, 2000).

No momento a pesquisa com a produção das páginas Web continua tendo continuidade nas turmas do Curso de Oceanografia da UNIVALI. A cada semestre estão sendo aprimoradas as técnicas aqui descritas e as formas de avaliação. Da mesma forma, vem sendo ampliada dentro da linha de Pesquisa em Educação e Estudos Ambientais do Mestrado em Educação da UNIVALI, a partir do desenvolvimento do Projeto EducAdo, que consiste na construção e uso pedagógico de um ambiente de aprendizagem cooperativa para Educação Ambiental em áreas costeiras, usando a Web como suporte (Guerra, 2000b, 2001). O mesmo está sendo desenvolvido com 15 professores(as) pertencentes a uma escola pública da região de Bombinhas-SC, outra da rede municipal de Itajaí e do Colégio de Aplicação da UNIVALI. A página Web do Projeto está disponível no endereço eletrônico http:// www.cehcom.univali.br/educado.

\section{AGRADECIMENTOS}

O autor agradece a Coordenadora do Curso de Oceanografia da UNIVALI, Prof ${ }^{a}$ Maria Inês Santos pela revisão crítica do texto, e aos alunos, hoje oceanógrafos e oceanógrafas, que produziram suas autorias disponibilizandoas como contribuição nas páginas Web do site da disciplina.

\section{REFERÊNCIAS BIBLIOGRÁFICAS}

Brasil. 1992. Ministério do Meio Ambiente. AGENDA 21. Conferência das Nações Unidas sobre o Meio Ambiente e Desenvolvimento. Brasília. Ministério do Meio Ambiente, Recursos Hídricos e Amazônia Legal.

Brasil. 1997. Ministério da Educação. Parâmetros curriculares nacionais: meio ambiente, saúde. Brasília: Secretaria de Educação Fundamental.

Belloni, M.L. 1999. Da tecnologia à comunicação educacional. Anais da 22a ${ }^{a}$. Reunião Anual da Associação Nacional de Pesquisadores em Educação - ANPED, Caxambú: ANPED, 24p.

Carneiro, S.M.C. 1999. A dimensão ambiental da educação escolar de $1^{a}$ a $4^{a}$ séries do ensino fundamental na rede pública da cidade de Paranaguá. Tese de Doutorado, Curitiba, Universidade Federal do Paraná.

Freire, P. 1980. Conscientização: teoria e prática da libertação. Uma introdução ao pensamento de Paulo Freire. 3 ed. São Paulo: Moraes.

Guerra, A.F.S. 1998 Projeto: Recursos informatizados como ambientes de ensino-aprendizagem: uma proposta experimental. Itajaí, CTTMar-UNIVALI.

Guerra, A.F.S. 1999. Uma experiência utilizando páginas WWW para educação ambiental. In: 2. SEMINÁRIO DE PESQUISA EM EDUCAÇÃO DA REGIÃO SUL. Anais... Curitiba, UFPR, 10 pp. 
Guerra, A.F.S. 2000. Aprender e ensinar usando a Web: uma experiência para a Educação Ambiental em áreas costeiras. In: Anais do Workshop de Informática Educativa. Curitiba, Sociedade Brasileira de Computação/PUCPR, 2000. 1CDROM.

Guerra, A.F.S. 2000. Projeto EducAdo: uma proposta de ambientes de aprendizagem cooperativa para educação ambiental em áreas costeiras usando a Web como suporte. Itajaí, UNIVALI.

Guerra, A.F.S. \& J.E. Taglieber. 2000. Uma reflexão sobre a dimensão ambiental na educação e as representações docentes. In: Anais do $3^{\circ}$ Seminário de Pesquisa da Região Sul. Porto Alegre, ANPED-SUL/ UFRGS, 16pp. 1CDROM.

Guerra, A.F.S. 2001. Diário de Bordo: Navegando em um Ambiente de Aprendizagem Cooperativa para Educação Ambiental. Tese de Doutorado, Florianópolis, Universidade Federal de Santa Catarina.

Guattari, F. 1993. As três ecologias. 4. ed. Campinas, Papirus.

Guimarães, M. 1995. A dimensão ambiental na educação. 3. ed. Campinas, Papirus.

Guimarães, M. 2000 Educação Ambiental Temas em Meio Ambiente. Duque de Caxias, Unigranrio.

Jonassen, D. 1996. O uso das novas tecnologias na educação a distância e a aprendizagem construtivista. Em Aberto, Brasília, (70): 70-88. abr/jun.

McConnel, D. 1994 Implementing computer supported cooperative learning. London: Kogan Page.

Medina, N.M. 1994. Elementos para a introdução da dimensão ambiental na educação escolar - 1ํo grau. In: Amazônia: Uma Proposta Interdisciplinar de Educação Ambiental. Brasília, IBAMA.

Polette, M. 1999 Migrações internas, urbanização e desenvolvimento: A aplicação de um modelo de desenvolvimento de balneários: Estudo de caso do processo de urbanização de Balneário Camboriú-SC. (mimeo).
Reigota, M. 1995 Meio ambiente e representação social. São Paulo, Cortez. (Col. Questões de nossa época, n.41).

Santos, M.I.F. dos. 1999. Novas perspectivas para o ensino de Oceanografia. Itajaí, Boletim Informativo AOCEANO. (3) p. 5.

Santos, M.I.F. dos \& P.J.C. VIEIRA. 1999. Diretrizes curriculares para os cursos de Oceanografia. Itajaí, Boletim Informativo AOCEANO. (3) p. 6-7.

Toledo, J.R. de. 1997. Censo revela metrópoles emergentes nos anos 90 . Folha de S. Paulo, 16 fev. 1997.Caderno 1, p. 9.

Trajber, R. \& L.H. Manzochi. 1996. Avaliando a educação ambiental no Brasil: materiais impressos. São Paulo: Gaia.

Trajber, R. \& L.B. Da Costa. (Org.) 2001. Avaliando a Educação Ambiental no Brasil: Materiais Audiovisuais. São Paulo: Peirópolis: Instituto Ecoar para a Cidadania.

Zucchi, R.A. 1997. Redes eletrônicas como instrumento de trabalho do pesquisador. In: Anais da 49aㅡ Reunião Anual da Sociedade Brasileira para o Progresso da Ciência. Belo Horizonte: SBPC/UFMG, 1997. v.1, p. 483-4.

\section{NOTAS}

Dimensão Ambiental é um termo utilizado por Mauro Guimarães $(1995,2000)$ e também por Sônia Carneiro (1987, p. 26-28, 1999, p. 261). A mesma define a Dimensão Ambiental na educação como o conjunto integrado de perspectivas ou aspectos de conteúdo e método para o desenvolvimento da educação ambiental no contexto de um dado currículo escolar (...), com enfoque de três dimensões: a cognitiva - conhecimentos científico escolares e saberes de professores, alunos e outros atores sociais quanto à questão ambiental; a metodológica - tratamento pedagógico-didático da realidade ambiental como conteúdo do conhecimento; e a afetivo-social - desenvolvimento atitudinal de professores e alunos a respeito da questão ambiental. 


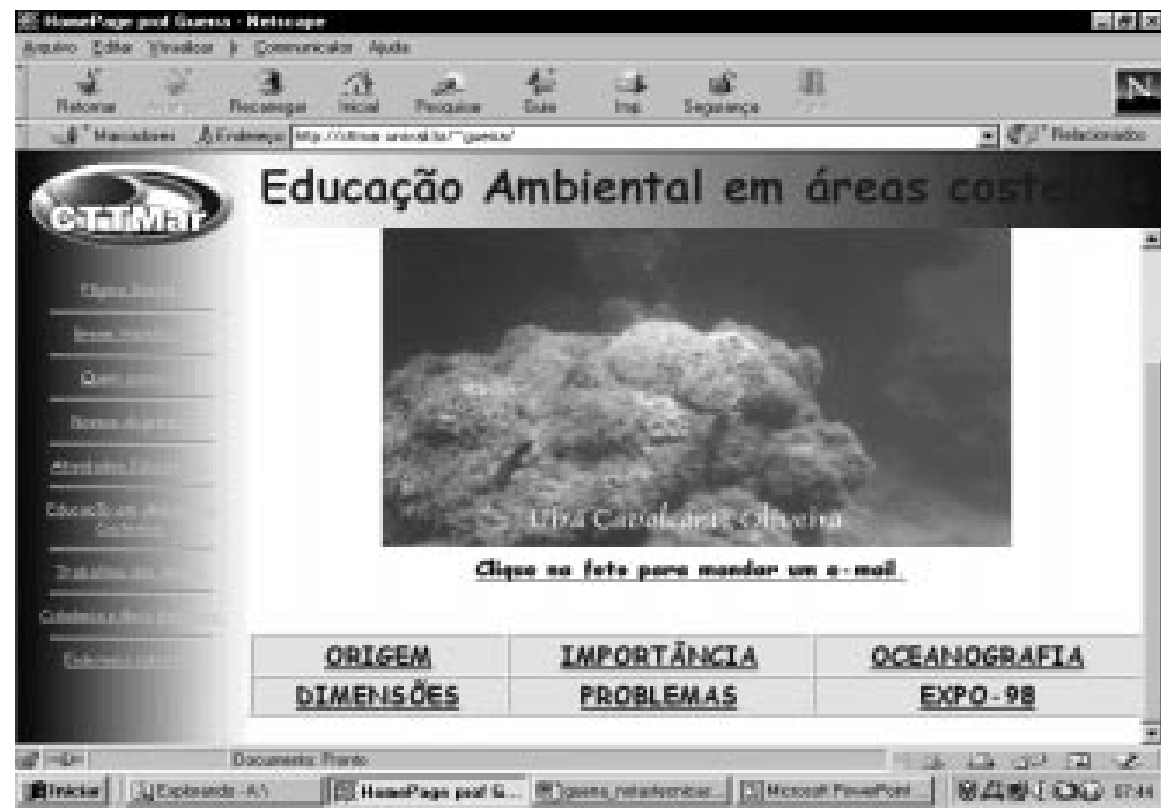

Figura 1: Abertura da Páginas Web "Oceanos" no site da disciplina

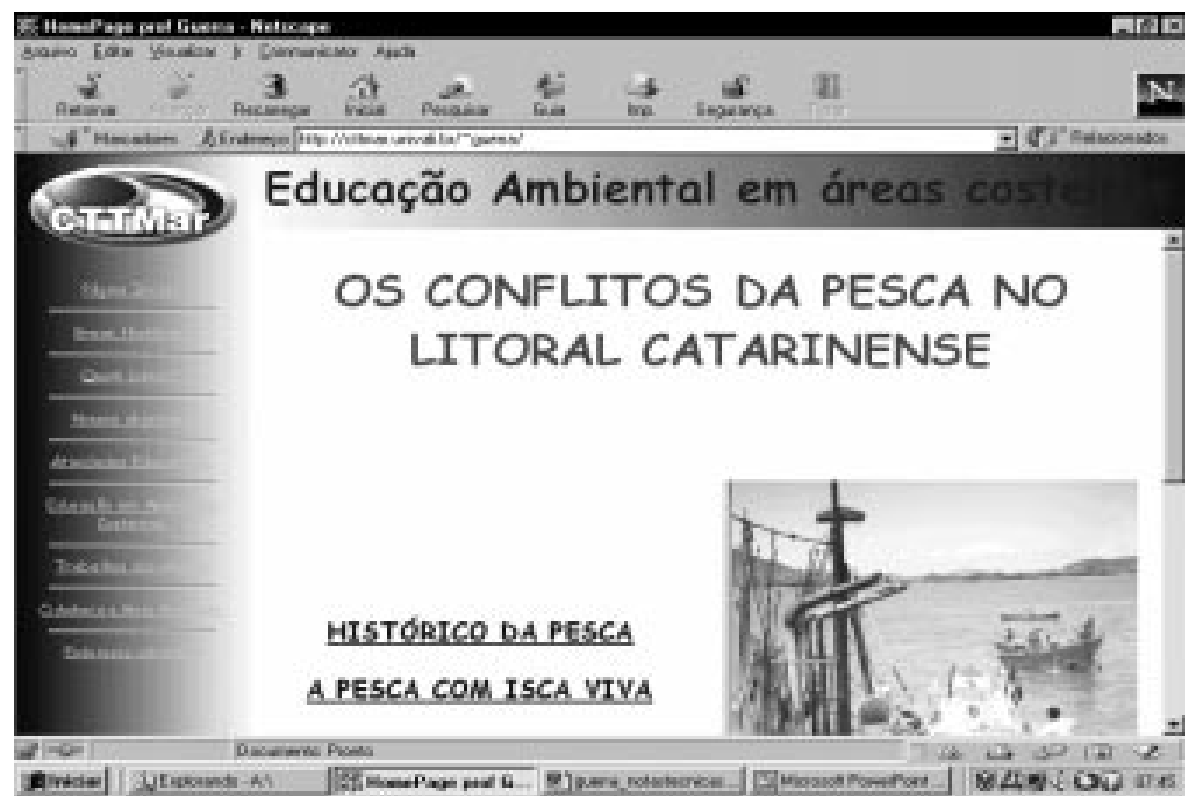

Figura 2: Abertura da Página Web "Conflitos da pesca no litoral catarinense" produzida pelos alunos 


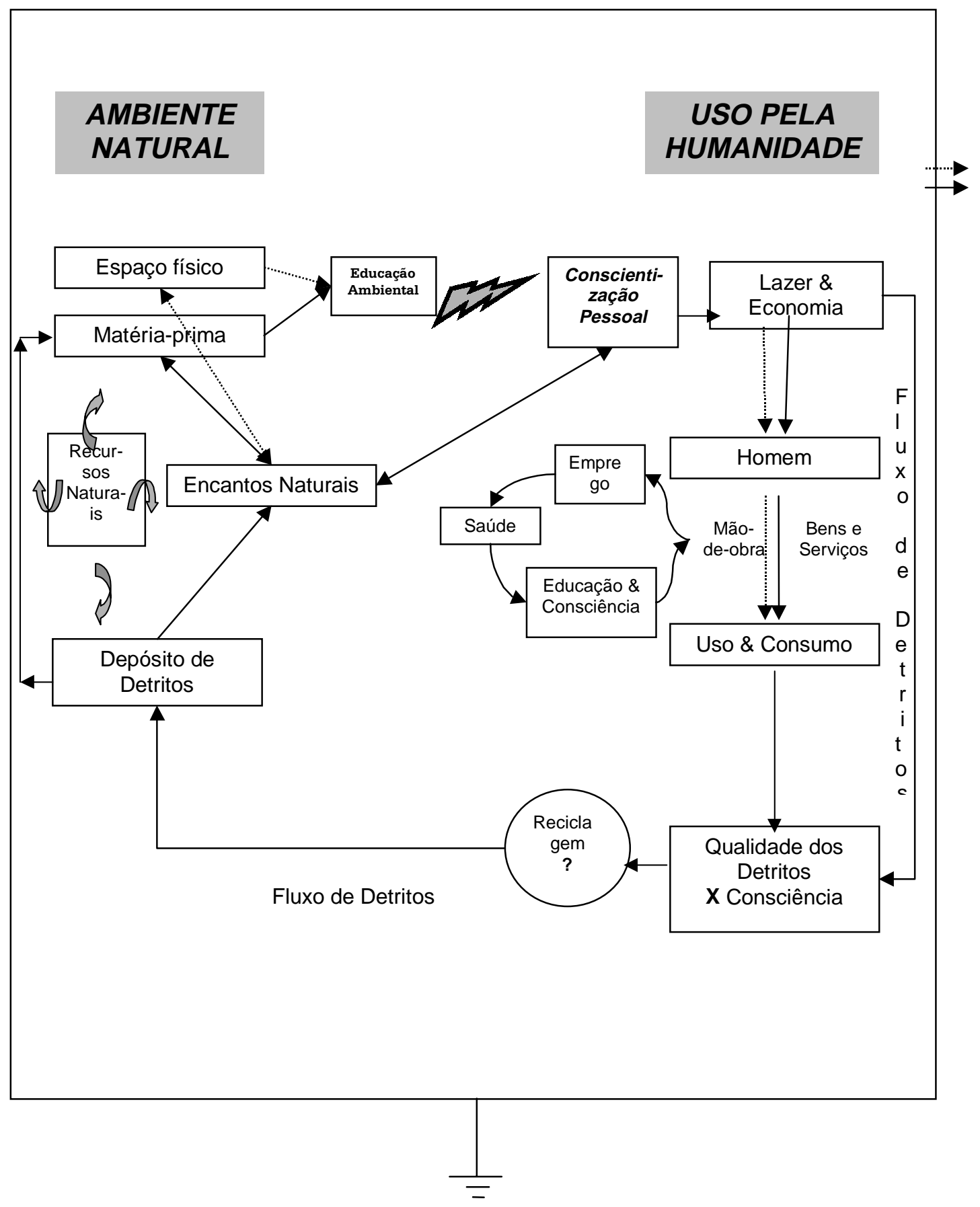


Anexo 2: Exemplo de mapa conceitual elaborado pelos alunos (Narbal e Inaê)

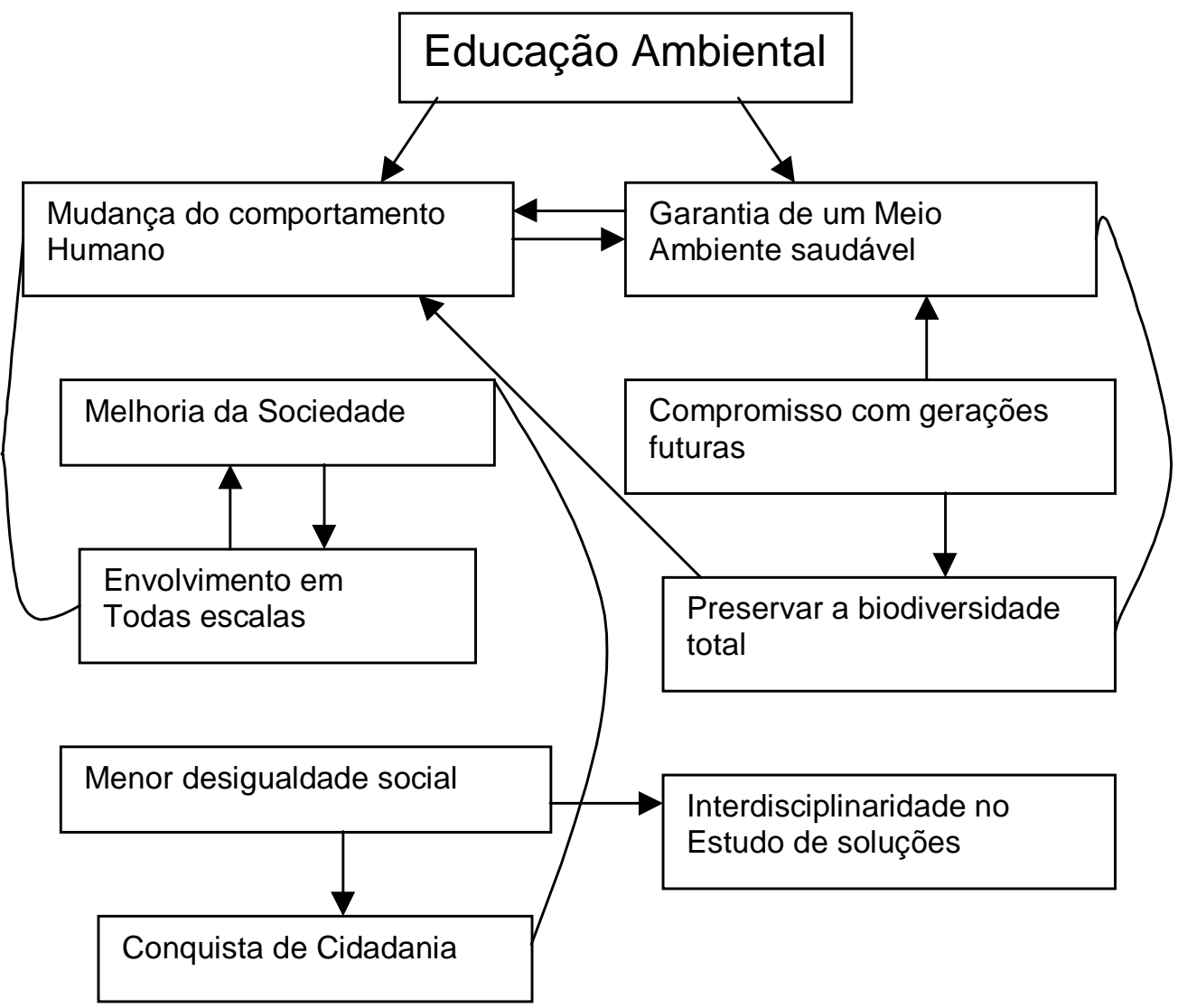

